\title{
GREEN INTELLECTUAL CAPITAL - A COMPREHENSIVE REVIEW AND OPPORTUNITIES FOR FUTURE RESEARCH
}

\author{
Lavinia-Mihaela BECEA ${ }^{a}$, Anca BORZA ${ }^{b}$ \\ ${ }^{a, b}$ Babes-Bolyai University, Cluj-Napoca, Romania
}

\begin{abstract}
For the last several years, sustainability has become a focal point not only for researchers but also for practitioners. In this light, the academic literature has considered green intellectual capital (GIC) as a critical agent which impacts the organizations' sustainable development strategies. Despite the growing body of research on GIC, this area has gained little attention and there are many opportunities for future research. Thus, the objective of this paper is to provide an overview of the strategic role of GIC in achieving corporate performance and also to identify possible future research trends regarding this area. Based on 37 reviewed articles, we found that the concept of GIC has gained increasing importance for researchers, particularly in the last few years. Also, the existing literature focuses more on the correlation between GIC and environmental performance, leaving room for further research regarding the other two pillars of sustainability (economic and social aspects). Finally, we proposed some future research directions for academics and practitioners.
\end{abstract}

KEYWORDS: competitive advantage, green intellectual capital, sustainability, triple bottom line perspective.

\section{DOI: 10.24818/IMC/2021/05.01}

\section{INTRODUCTION}

The rapid economic growth has come with several environmental changes as water pollution, deforestation and global warming, impacting markets and businesses all around the world (Jin et al., 2020). Although some firms do not feel guilty for environmental degradation, there is pressure coming from the government, stakeholders and customers to act responsibly towards the environment (Murillo-Luna et al., 2008; Nisar et al., 2021) and to adopt green strategies in order to achieve sustainability (Jirakraisiri et al., 2021). As a result of global environmental concern, in 2015 was launched the United Nations'Sustainable Development Goals (SDGs) which act as a global plan to obtain sustainable development by 2030. This framework includes 17 sustainable development goals that embrace economic, environmental and social issues (Secundo et al., 2020). In light of the above, the topic of corporate sustainability has become a focal point for both academics and practitioners, further research being necessary in order to create a framework that can facilitate the achievement of the ambitious global goals of the 2030 Agenda.

Within this debate, more researchers consider intangible assets more valuable than tangible assets, particularly when it comes to gaining a competitive advantage (Chaudhry et al., 2016; Rehman et al., 2021; Shah et al., 2021). From this perspective, some researchers start to think about green intellectual capital (GIC) as a new environmental strategy that enables firms to differentiate themselves from other competitors as well as to achieve sustainable development (Bombiak, 2021). The concept of GIC was proposed by Chen in (2008), and it refers to all types of firms' intangible

\footnotetext{
* Corresponding author. E-mail address: lavinia.becea@econ.ubbcluj.ro
} 
resources i.e. knowledge, capabilities, cooperations, which are related to green protection and green innovation. Like intellectual capital, the GIC construct embraces three categories of intangible resources, namely human, structural and relational capital.

According to Yusoff et al. (2019), GIC is a possible solution for environmental issues. Also, some researchers proved the significant role of green activities in achieving environmental and economic performance (Wang \& Juo, 2021). The same authors claimed that an efficient environmental strategy will be achieved if managers invest in GIC development. Moreover, a recent study claimed that GIC can support firms in achieving environmental, economic and social performance (Yusliza et al., 2020).

Despite the above, limited literature is available about the GIC concept and its contribution to corporate performance (Wang \& Juo, 2021). A recent study by Bombiak (2021) argued that the level of GIC development is low because many managers are not aware of this concept. Moreover, Yusliza et al., (2020) also signalized the limited knowledge of managers about GIC management and its beneficial role in achieving better results. In view of this, the purpose of the present study is to conduct a literature review on GIC aimed to provide an overview of the strategic role of GIC in achieving sustainability, using the triple bottom line approach. This paper also aims to give insights into the possible future research trends regarding GIC policy. Based on the previous considerations, we propose the following research questions: How has literature addressing GIC evolved so far? What are the possible future research lines regarding GIC?

In order to perform the present review, we analyzed 37 articles related to the GIC concept, found on Google Scholar and the Web of Science database. We looked at how GIC literature has evolved so far, which are the most cited papers and what strategic role has GIC played in achieving corporate performance. The results highlight that the topic of GIC has gained researchers'attention, especially in the past several years. The findings also revealed that the literature has focused mainly on three areas: 1) GIC and competitive advantage; 2) GIC and business sustainability 3) GIC and sustainability under the triple bottom line perspective. Although the literature has shown a positive relationship between GIC and corporate performance, this field is still considered a topic of growing importance in the management literature. In the end, we suggested future research directions, emphasizing the lack of research addressing the role of GIC in enhancing social performance.

This study serves as a reference paper for academics with regard to the evolution of the GIC concept as a driver for corporate sustainability. Also, it provides several insights for future research agenda, outlining the emerging trend of sustainability. In terms of practical implications, the current study revealed the strategic role of GIC in supporting the achievement of business sustainability. This paper is structured in this manner. After the introduction, the next section presents a theoretical framework regarding the GIC construct. A detailed methodology is presented in section three and the main findings in section four. Finally, the last section shows the conclusion and proposes future lines of research.

\section{THEORETICAL BACKGROUND}

In the last decades, intellectual capital has become a subject of interest for scholars and its significant role in enhancing the company value was recognized by most researchers (Yong et al., 2019; Hermawan et al., 2020; Nisar et al., 2021). The concept evolved through different stages, reaching a total of five development levels. The first stage focused on creating a common terminology for the IC concept (Guthrie et al., 2012). The second phase was preoccupied with finding methods to measure, manage and report IC. According to Dumay and Garanina (2013), a critical examination of how IC is implemented inside organizations was the main focus of the third stage of development. More recently, the fourth stage extended IC's boundaries by analyzing how it can create value with a wider ecosystems focus, including nations, cities and communities. In this 
regard, a new wave of studies was developed examining the impact of IC on society and the environment (Secundo et al., 2013). Further, Minoja \& Romano (2021) indicated in their recent study that there is a fifth stage of development concerning the IC concept. This stage offers a new approach for researchers to extend the theoretical perspective of the concept by analyzing the role that IC plays in achieving sustainability under the triple bottom line perspective. In other words, there is a new trend in literature that aims to examine which practices of IC can enhance sustainability concerning all its dimensions (social, economic and environmental).

According to Meadows et al. (1993), the link between a firm's intellectual capital and its environmental footprints was ignored in the literature. An explanation for this fact could be that intellectual capital is not suitable to investigate environmental issues, due to the lack of a "green" component (Jirakraisiri et al., 2021). With this in mind, noteworthy is Chen's (2008) work which proposed a novel concept: green intellectual capital (GIC) which encompasses aspects of intellectual capital (IC) that corresponding to green innovation and environmental protection. The study also proved that the investment in GIC will enable firms to comply with environmental regulations and also to achieve a competitive position in the market. This finding is in line with Huang \& Kung, (2011) and Chang \& Chen (2012) who shed light on the sound role GIC played in gaining better performance.

The definitions of GIC are rare in the management literature (Delgado-Verde et al., 2014). In her groundbreaking study, Chen (2008) defined GIC as all the intangible resources of a company, i.e. knowledge, capabilities, cooperations, which are related to green protection and green innovation. Apart from Chen's work, few studies have analyzed IC concerning environmental aspects. Yong et al., (2019) described GIC as the mix of "green and environment familiarity sources and understanding capacity" that help an organization to achieve a competitive advantage. More recently, GIC was defined by Villiers \& Sharmac (2020) as the knowledge that a company needs to properly manage environmental actions in order to gain a competitive advantage. Under the traditional construct of IC (Bontis, 1999), GIC encompasses three core elements: human, structural and relational capital.

Green human capital (GHC) relates to the environmental knowledge, abilities, experiences, commitments, etc. that are embedded in employees (Chen, 2008). At the same time, green structural capital (GSC) refers to everything that a company owns when their employees go home: organizational capabilities and commitments, organizational culture, knowledge management system, company images, etc., all related to the environment (Chang \& Chen, 2012). Green relational capital (GRC) is known in the literature as all the company's relationships with customers, vendors, and other strategic partners regarding green management and green innovation (Chang \& Chen, 2012).

Most of the studies claimed that firms'investment in GIC brings real benefits (Yahya et al., 2015) and it assists firms in achieving the edge over other companies (Huang \& Kung, 2011; DelgadoVerde et al., 2014; Chaudhry et al., 2016). Other studies stressed that by giving importance to GIC, companies will be able to enhance sustainable performance concerning the triple bottom line approach (Yusliza et al., 2020; Omar et al., 2019; Ullah et al., 2021). Moreover, it was proved that GIC has a significant role in adopting green human resource management practices (GHRM) (Yong et al., 2019b), it is a key driver of green innovation adoption (Ali et al., 2021; Wang \& Juo, 2021; Rehman et al., 2021; Jirakraisiri et al., 2021) and it is a guiding factor in adopting green strategies (Amores-Salvadó et al., 2021). However, a recent study (Bombiak, 2021) signaled that many managers are unaware of the GIC concept and because of that, there is a low level of green practices implemented within companies. That could be a consequence of COVID-19 due to the insufficient resources of companies to attribute for GIC development. In the same vein, Yusliza et al., (2020) highlighted the problem of limited knowledge about intellectual capital related to environmental issues. 
Having in mind that GIC has only recently emerged as a significant topic for both academics and practitioners (Yong et al., 2019b; Martín-de Castro et al., 2020) we can ascertain that this field is still poorly studied and there are multiple opportunities for future research (Wang \& Juo, 2021; Nisar et al., 2021; Jirakraisiri et al., 2021). Hence, the purpose of the present study is to offer an overview of the academic literature that frames this area and also to provide insights into what issues could be tackled in future studies. Hence, the main research questions are:

RQ1: How has literature addressing GIC evolved so far?

RQ2: What are the possible future research lines regarding GIC?

\section{METHODOLOGY}

In order to fulfill the objectives of this study, we performed a systematic review of the articles published so far concerning the GIC construct. In this way, we obtained a global outlook of how the GIC concept has evolved so far and what areas have been scarcely treated or neglected by the researchers.

To collect the sample articles, we perceived a systematic investigation on the Web of Science (WoS) database. Additionally, to make sure that we do not neglect any pertinent article from the literature, we carried out a manual investigation on Google Scholar (GS).

Next, the research process was divided into two phases. Firstly, we created our database by extracting articles from the two main databases abovementioned. To identify articles consistent with the research objective, we searched specific keywords as "Green Intellectual Capital", "GIC", "Green IC", "Green performance" "Green intellectual capital \& sustainability". Having in mind that GIC does not have a long history in the literature, we did not select any time frame, so we considered all documents published until 2021. Secondly, a content analysis of each article was conducted in order to select the most relevant papers. Hence, after we read all titles and abstracts and we eliminated irrelevant studies and duplicates, a total of 37 articles was ultimately closely examined.

\section{DESCRIPTIVE ANALYSIS OF THE SYSTEMATIC REVIEW}

\subsection{Evolution of publications over time}

Figure 1 displays the distribution per year of the articles regarding the GIC concept. At first glance, it is evident that GIC does not have a long history in the literature. However, since the first publication in 2008 , there has been a growing number of studies related to the GIC construct, particularly over the past couple of years.

As shown by the figure 1, in the last three years, the subject was recurrently approached by academics, reaching two peaks: in 2019 (10) and 2021- until August (16). A possible reason why the analyzed topic has flourished in recent times could be related to the steady growth of environmental consciousness management (Ali et al.,2021) and stakeholders' pressure exercised on firms to adopt green practices (Zameer et al., 2020; Yasmeen et al., 2020). Additionally, another reason could be the launch of the Sustainable Development Goals (SDGs) which is a global plan to obtain a sustainable future by 2030. In this context, looking for methods to assist the achievement of the SDGs, environmental management has increasingly attracted scholars' attention, being perceived as a key resource to achieve ambitious global goals (Secundo et al., 2020).

Despite the fact that the GIC concept has gained more attention from researchers lately, there is still a small number of studies addressing this topic in the management literature. Consequently, much room is left for academics to discuss the topic in more detail and to approach it from different perspectives. 


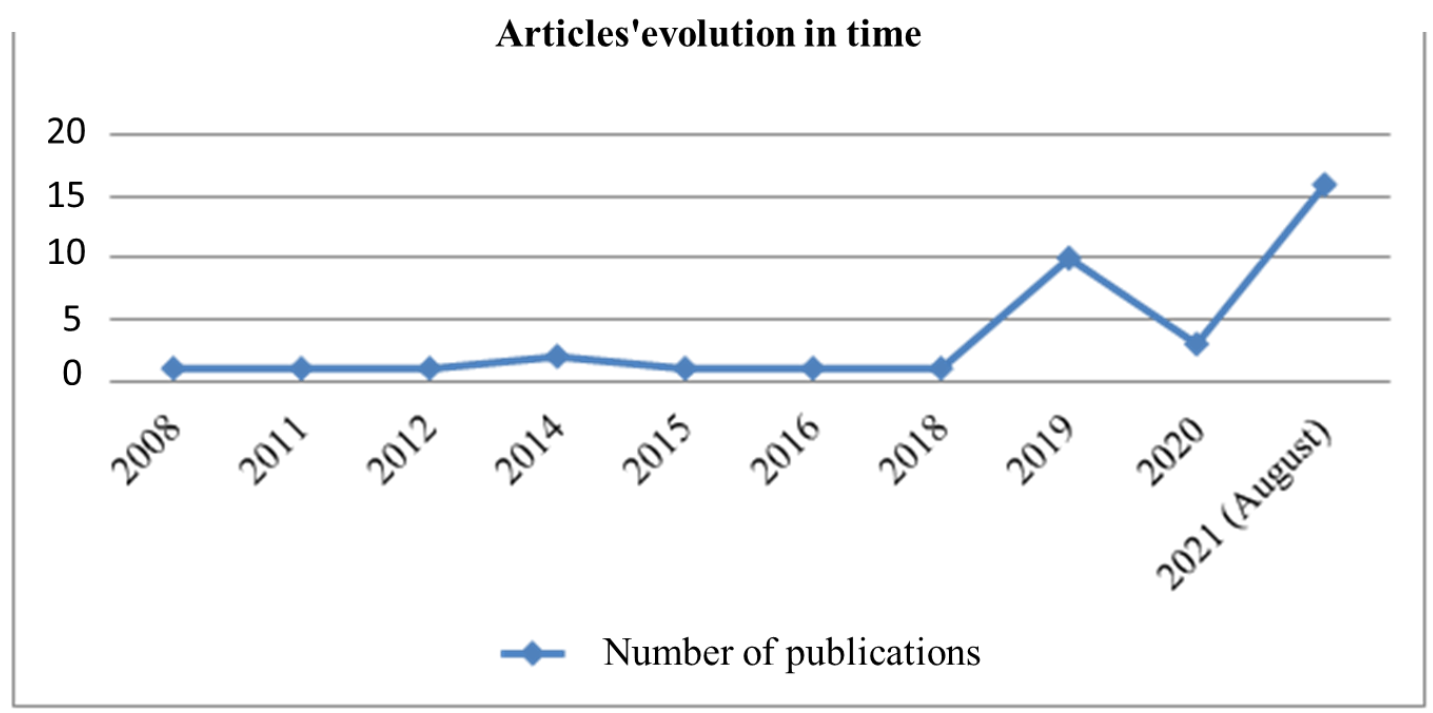

Figure 1. Articles' evolution in time

Source: own editing, based on literature review

\subsection{Relevance of articles}

Table 1 reveals the most three influential documents published over the 2008-2021 (until August) timeframe. In order to select them, the received citations (TC) were used as a measurement unit and the statistics were retrieved from the Google Scholars database. In addition, the table shows the average number of citations per year for each article.

Therefore, as it is presented in the table, the revolutionary study of Chen (2008) is the most significant document in GIC literature, receiving almost 41 citations every year since publication. This result was expected, considering the fact that in this study, Chen conceptualized the GIC construct. Henceforth, the concept began to spread in the management literature.

Four years later, in 2012, another notable work was done and it has a major implication in giving insights about green activities. In their paper, Chan and Chen (2012) evaluated the contribution of corporate social responsibility (CSR) and environmental consciousness in achieving GIC. It seems that the framework they developed in this study become a reference point for researchers to further analyze more determinants for GIC i.e environmental capabilities (Albertini, 2021), environmental legislation (Trevlopoulos et al., 2021), firm's size, management ownership's structure, profitability (Augustine \& Dwianika, 2019), green innovation (Rehman et al., 2021).

This paper is followed by another valuable work of Yong et al., (2019). In this research, the authors pointed out that GIC can be seen as the main factor that leads to the adoption of green HRM practices. In other words, if companies invest in environmental knowledge development and application, have specific systems which enable them to facilitate information-sharing and are also open to build "green relations" with stakeholders, the employees will be more involved in environmental activities. Further, as Nivlouei and Khass (2014) asserted, those efforts will increase the chances of organizations to gain a green competitive advantage. Hence, considering the number of citations received up to date (111), we can assume that this article became a reference point for researchers. However, it is important to highlight that even if this article was ranked third, the number of citations received per year is almost triple that the number of citations received by the previous article of Chan and Chen. 
Table 1. The top 3 articles per number of citations received

\begin{tabular}{|c|l|l|c|l|c|c|}
\hline & \multicolumn{1}{|c|}{ Author $(\mathbf{s})$} & \multicolumn{1}{|c|}{ Title } & Year & \multicolumn{1}{|c|}{ Journal } & TC & TC/Y \\
\hline $\mathbf{1}$ & Chen, Y. S & $\begin{array}{l}\text { The positive effect of green } \\
\text { intellectual capital on competitive } \\
\text { advantage of firms }\end{array}$ & 2008 & $\begin{array}{l}\text { Journal of } \\
\text { business } \\
\text { ethics }\end{array}$ & 571 & 40.78 \\
\hline $\mathbf{2}$ & Chang \& Chen & $\begin{array}{l}\text { The determinants of green } \\
\text { intellectual capital }\end{array}$ & 2012 & $\begin{array}{l}\text { Management } \\
\text { decision }\end{array}$ & 128 & 12.8 \\
\hline $\mathbf{3}$ & Yong et al. & $\begin{array}{l}\text { Nexus between green intellectual } \\
\text { capital and green human resource } \\
\text { management }\end{array}$ & 2019 & $\begin{array}{l}\text { Journal of } \\
\text { cleaner } \\
\text { production }\end{array}$ & 111 & 37 \\
\hline
\end{tabular}

Source: own editing based on the literature review

\section{CONTENT OF THE SELECTED ARTICLES}

In the next section, we present the main findings that we gather from the selected articles. In order to have a clear idea about what has been done before and what is known on this topic, we divided the findings with regards to the role of GIC in enhancing corporate performance. Therefore, this section considers three of the most studied research topics:

1. GIC and competitive advantage;

2. GIC and sustainability;

3. GIC and triple bottom line perspective of sustainability.

\subsection{GIC and competitive advantage}

Besides the environmental harassment, which became a global concern at this time, the rapid economic development drastically changed the pattern of competitive models. More specifically, in order to cope with environmental issues and to obtain competitive benefits, organizations need to concentrate on the environment by developing green capabilities and by adopting strategies that could enhance the firm's ability to lessen the negative impact on the environment (Nivlouei \& Khass, 2014; Nisar et al., 2021).

Analyzing the selected articles, we noticed that eight out of thirty-seven papers address the link between GIC and competitive advantage. Also, this association gained the researchers' attention particularly during the first years of development, majority of the articles addressing this subject being published over the 2008-2016 timeframe. Thus, the role of GIC in gaining a competitive position was examined by several researchers, each of them approaching the topic in a different context and from various perspectives.

Most of the researchers have recognized the impact of GIC in enhancing the firm's ability to obtain a competitive position in the market (Augustine \& Dwianika, 2019). For instance, in her pioneering research in Taiwan, Chen (2008) claimed that all three elements of GIC (green human capital, green relational capital and green structural capital) have a positive impact on competitive advantage. More explicitly, firms that successfully implement GIC, not just comply with environmental regulations, but also can achieve a competitive position in the market. The findings are consistent with Nivlouei \& Khass (2014)' results, which confirm the meaningful relationship between all elements of green IC and competitive edge.

Some other studies analyzed GIC as a mediator variable. For instance, the study of Huang \& Kung (2011) found that the path between environmental consciousness and competitive advantage is mediated through green IC. According to their findings, if an organization is environmentally aware, has skilled employees, strong relation with stakeholders and a proper knowledge management system, it means that the company is concern about environmental issues and in this regard, the company will achieve the edge over its competitors. The results are in line with 
Chaudhry et al., (2016), which also indicate that the environmental consciousness of a firm is not automatically translated into a competitive advantage, so firms need to properly manage their GIC in order to differentiate their offering on the market and to obtain financial performance.

A different approach had Yahya et al., (2015) which, unlike previous studies, referred to GSC as a combination between green organizational capital and green innovation. The results revealed that the more firms invest in GHC, GRC and green innovation, the stronger the competitive advantage is. However, there is a negative association between green organizational capital and competitive advantage. To clarify the last result, further research is needed to discover why green organizational asset does not directly contribute to better positioning in the market.

More recently, Sidik, et al., (2019) have performed an analysis of 127 SMEs in the manufacturing sector of Indonesia. The paper demonstrates that if importance has been given to GIC, energy efficiency and environmental management accounting system, those will create a competitive position for the organization. Another recent paper of Cahyono and Hakim (2020) examined the moderating effect of Islamic business ethics in between GIC and competitive advantage. According to them, investment in intangible assets related to the environment (GIC) is beneficial for SMEs for two reasons. Firstly, it will enable firms to cope with stakeholders' pressure to adopt environmental strategies and secondly, firms will have higher chances to gain a competitive edge. Moreover, the empirical results revealed that a firm showing interest in Islamic ethical values i.e. honesty and trust are more likely to achieve a robust position on the market through the incorporation of GHC.

In 2021, due to the emerging trend in sustainable development, a different perspective has been approached by Astuti and Datrini (2021) regarding the role of GIC in gaining a competitive position for the firms. Concretely, they extended the traditional framework by examining the contribution of green IC and environmental consciousness in achieving green competitive advantage. The results entailed significant insights related to the fact that an organization that invests in GIC will be able to achieve the edge over other companies and to promote sustainable development. In other words, firms providing training and development for their employees as a means to motivate them to practice green behavior, also obtain a competitive advantage over their rivals. Also, a green competitive advantage is the outcome of the adoption of a proper environmental management system. In the same vein, giving attention to green relationships will significantly assist the companies in obtaining services and goods that are difficult to imitate by rivals.

\subsection{GIC and sustainability}

The topic of sustainable development gained more attention from researchers and practitioners due to the growing environmental attentiveness (Chaudhry et al., 2016) which leads to constant pressure for companies to comply with environmental regulations and to adopt green strategies (Nivlouei \& Khass, 2014). Moreover, the 2030 Agenda for Sustainable Development serves as a plan to obtain a sustainable future for all (Secundo, et al., 2020). Under these circumstances, organizations have no choice but to keep up with the new trend of ,growing green and becoming sustainable" (Chang \& Chen, 2012) and to be willing to invest more resources and efforts in decreasing the negative impact on the environment (Popescu, 2019).

Within this debate, some researchers considered the concept of GIC as a new pattern of sustainable development that attempts to help organizations to achieve sustainable goals (Martins, et al., 2019; Popescu, 2019). In this regard, we can cite the research of Yusoff et al. (2019) which examined the role of green IC in achieving business sustainability. They pointed out that sustainable performance is an outcome of the adoption of green structural capital (GSC) and green relational capital (GRC), while the adoption of green human capital (GHC) does not come along with more sustainable practices. These findings contradict the result obtained by Delgado-Verde et al., (2014) Malik, et al., (2020) and Sabir et al., (2020) which claimed that all three components of GIC significantly assist in obtaining sustainable outcomes. 
Attempting to explain the abovementioned linkage, Omar et al. (2019) examined the effect of green intangible assets on business sustainability, in the presence of organizational learning capability (OLC). The empirical results indicate that by establishing green relations with stakeholders and by adopting an environmental management system, firms indirectly contribute to sustainable performance through organizational learning capability. In contrast, the path between GHC and business sustainability is not mediated through the firm's ability to process, create, transfer and integrate knowledge (Jerez-Gomez, et al., 2005). From the viewpoint of Sabir et al., (2020) in order to gain sustainable outcomes, a firm has to consider all three dimensions of GIC. Additionally, this research proved the exact opposite of what Omar et al., (2019) claimed, recognizing the significant role of OLC as a mediator element just between GHC and sustainability. In other words, GHC not only directly affects sustainability but is also the only dimension that indirectly affects it through OLC. Further, a recent paper of Delgado-Verde (2014) investigated the correlation between GIC and sustainability, underscoring the moderation role of IT capabilities. Apart from the significant contribution of all variables indicating GIC in business sustainability, the results revealed the moderation effect of IT capabilities only between two components of GIC (GSC, GRC) and sustainability performance, while in the context of the third element (GHC), an insignificant moderation effect has been revealed.

\section{Triple bottom line perspective of sustainability}

Although the concept of the triple bottom line (TBL) appeared for the first time in the literature in 1997 (Elkington, 1997), the sustainability approach seen as a concern for three dimensions, namely economic, environmental and social, has constantly emerged in the management literature (Isil \& Hernke, 2017). In light of this perspective, TBL has become a dominant approach for sustainability in business, being considered a formula that enables firms to incorporate sustainability in order to achieve the SDGs (Isil \& Hernke, 2017; Popescu, 2019). Hence, we decided to pay close attention to those articles from the literature which have addressed the association between GIC and each dimension of sustainability, as is suggested by the TBL perspective.

\subsubsection{GIC- Economic Performance}

According to Yusliza et al. (2020), investment in all three dimensions of GIC will assist firms in obtaining financial performance. This finding is in line with Wang \& Juo (2021)'result, which states that financial performance is improved when firms invest in green intangible assets. Also, they stressed that the increase in GHC and GRC potentially leads to a higher green innovation which then enhances economic performance. In the same vein, Shang et al., (2019) claimed that green dynamic capabilities (GDC) fully mediate the path between GIC and economic performance. Concretely, the investment in green intangible assets does not directly lead to economic growth, on the contrary, in the absence of GDC, it can cause higher expenses. By analyzing the annual reports of 106 companies from Indonesia, Erinos \& Yurniwati (2018) concluded that GIC positively but not significantly affects financial performance. More precisely, value-added capital assets positively influence financial performance and the decrease of this variable will lead to an inefficient role of GIC on corporate performance.

Although the favorable results obtained by implementing GIC have been confirmed by several researchers, some companies still think about it as a barrier to their growth and performance (Sidik, et al., 2019). Moreover, Wang and Juo (2021) claimed that the link between green performance and financial benefits is perceived as a trade-off, managers thinking about it more like an expense than as a worthy investment. In addition, Yahya et al., (2015) affirmed that is difficult to reflect in the financial statement the contribution of GIC. 


\subsubsection{GIC-Environmental Performance}

Considering the previous section, we can state that much more papers have examined the contribution of GIC in enhancing firms' environmental performance. As proof, we can cite the work of Khan et al., (2021) and Yadiati (2019) who claimed that investing in GIC will significantly assist firms in obtaining environmental outcomes. In the same vein, Song and Yu (2018) and Sidik et al., (2019) stressed that green performance is positively influenced by green intangibles. Moreover, in their study, Yusliza et al. (2020) also considered GIC as a significant driver to environmental performance. Despite the above, Shah et al. (2021) found that only GHC and GRC influence green performance, while contrary to expectation, GSC has a negative effect on firms' environmental performance.

On the other hand, several studies examined the relationship in the presence of different variables, intending to define models which can improve environmental behavior. For instance, Rehman et al., (2021) highlighted that green innovation moderates and mediates the relationship between GIC and firms' environmental performance. Similarly, besides the positive relation between green IC and green performance, the study of Wang and Juo (2021) also found evidence to support the mediation role of green innovation between GSC, GRC and environmental performance. Although green innovation does not seem to strengthen the GHC-environment performance relationship in this study, Mansoor et al. (2021) proved that in the presence of green human resource management as a mediator, firms can enhance environmental performance by investing in GHC. Additionally, they found that environmental health is improved when firms perceived GHC and GRC in a positive light. This last finding was validated by Trevlopoulus et al. (2021) who also considered that if firms give importance to environmental regulations, it will improve GIC and subsequently will enhance green performance. According to Shah et al., (2021), the path between all dimensions of GIC and green performance is mediated through environmental responsibility. In a different perspective, Delgado-Verde et al. (2014) stressed that GRC has a positive and linear relation with green performance and, at the same time, it mediates the path between GSC and green product innovation.

\subsubsection{GIC- Social Performance}

Even though the sustainability challenge requires managers to take into consideration the issue of social sustainability, this aspect was scarcely tackled in the management literature. As far as we know, until now only Yusliza et al. (2020) have examined the contribution of GIC in achieving good social performance. The results revealed that firms committed to invest and develop green activities will bring benefits for society.

Some of the main contributions that lead to this association are provided by resource-based view (RBV) theory which refers to corporate social responsibility as a capability that enables firms to achieve sustainable development, by improving corporate image and by establishing a good relationship with stakeholders (Hart, 1995).

\section{CONCLUSIONS AND FUTURE RESEARCH DIRECTIONS}

This review aims to investigate the literary corpus addressing the green intellectual capital (GIC) concept, emphasizing its contribution to achieving all three dimensions of sustainability namely environmental, economic and social dimensions, which act together in order to ensure a sustainable future. In this regard, we analyzed 37 GIC-publications found in the Web of Science and Google Scholar database, and we paid close attention to how publications regarding GIC have evolved so far, which are the most relevant papers which contribute to the GIC literature and what is the role played by this concept in achieving sustainability under the triple bottom line perspective.

The results of the current study showed that the subject of GIC has been frequently approached by researchers, particularly over the last few years. From this perspective, we can affirm that the GIC concept is a focal point of research in these times, therefore scholars should address this topic more 
in order to identify in which conditions the GIC concept can be considered a valuable resource. Moreover, following the current trend of sustainable development, the principle of sustainable intellectual capital (SIC) should provide interesting and valuable research lines that deserve further attention (Cavicchi \& Vagnoni, 2017).

In the same line, the finding that one of the most cited papers related to GIC was published recently (2019), confirms the high interest of researchers in perceiving this concept as a tool in order to cope with environmental concerns. Consequently, much room is left for researchers to examine this area of "growing green and becoming sustainable" (Popescu, 2019)

Furthermore, after an in-depth content analysis of the selected articles, we found that the main issues concerning GIC are related to corporate performance. Concretely, in their studies, researchers mostly associated GIC with competitive advantage and sustainability, both as a single concept and the triple bottom line perspective.

In this regard, limited literature is available about how GIC enhances the firm's ability to gain a competitive advantage. This issue was approached particularly in the first years of GIC development but, as Nivlouei and Khass (2014) assumed, the growing trend of environmental attentiveness has changed the current patterns of competition. Hence, great space is left to explore this topic in more detail, having in mind the new market context which encourages green approaches. For instance, not many researchers have focused on the new concept of green competitive advantage, so it could be a new focal point of research for academics. Also, the majority of studies were carried out in the manufacturing industry, so it would be interesting to assert whether GIC matters for CA in the service sector (Ali et al., 2021). According to Yahya et al., (2015), no evidence was found to prove the positive association between green organizational capital (GOC) and competitive advantage. Hence, further research is needed to find the reason why GOC does not directly contribute to a competitive position in the market. Also, future studies should include other variables in this framework in order to obtain a broader perspective of how intangible assets could help firms to differentiate themselves from competitors.

Further, our research shows that significant importance has been paid to GIC as an antecedent for sustainability. In other words, GIC is perceived as a new pattern of sustainable development that enables firms to cope with environmental challenges. However, more studies should be done in order to generalize the positive effect of GIC on business sustainability. The present review shows that the path between the abovementioned variables is mediated by green human resource management (Malik et al., 2020), organizational learning capability (Omar et al., 2019), IT capabilities (Ullah et al., 2021). Future studies should consider more moderators and mediators in this framework, to improve our knowledge on how to manage green IC in order to achieve corporate sustainability. Moreover, a challenge for researchers is to internalize the core principles of the 2030 Agenda. Hence, they should continue to investigate the GIC impact on sustainability, looking for a framework to support the objectives of the 2030 Agenda with its 17 SDGs (Alvino et al., 2020).

Despite the above, to consider the triple bottom line perspective of sustainability when investigating GIC is a novel approach in the literature. When it comes to the contribution of GIC on economic performance, the opinions are divided. Some authors believe that a better economic performance is achieved when GIC is perceived in a positive light, while others claimed that an investment in green IC can bring additional expenses if it is not properly managed. Consequently, more research is needed to identify how to manage GIC in order to achieve better financial performance and no additional costs (Yusoff et al., 2019). Besides, future studies are encouraged to integrate into this framework other factors such as green human resource management, (Malik et al., 2020) or green innovation (Wang \& Juo, 2021) which can influence the effect of green activities on financial performance.

The environmental behavior as a result of GIC implementation is the most studied area concerning the TBL perspective of sustainability. Our findings confirm that the GIC approach is considered one 
of the best strategies to improve firms' environmental footprints. However, much room is left for in-depth analysis regarding this topic. For instance, there could be interesting results analyzing the mediation role of environmental innovation in achieving green performance (Rehman et al., 2021; Trevlopoulos et al., 2021). Also, future studies should determine which aspects of GIC have a greater influence on environmental performance (Nisar et al., 2021).

Surprisingly, not much effort has been directed towards understanding how investment in GIC can improve social responsibility so, social context should receive further attention from both academics and practitioners. Moreover, because sustainable development requires social improvement, researchers should examine how GIC can help firms to engage in corporate social responsibility and further, achieve the SDGs. Last but not least, future studies should propose more frameworks that examine the role of the GIC construct in achieving sustainability under the triple bottom line perspective.

The current paper gives insights for a better understanding of the GIC concept, by shedding light on the association between green activities, business sustainability and organizational performance. In terms of practical implications, this review gives an overall perspective about the critical role of GIC in supporting the achievement of business sustainability.

\section{REFERENCES}

Albertini, E. (2021). What are the environmental capabilities, as components of the sustainable intellectual capital, that matter to the CEOs of European companies? Journal of Intellectual Capital, ahead-of-print. doi:10.1108/JIC-06-2020-0215

Ali, W., Jun, W., Hussain, H., Khan, N. A., Younas, M. W. \& Jamil, I. (2021). Does green intellectual capital matter for green innovation adoption? Evidence from the manufacturing SMEs of Pakistan. Journal of Intellectual Capital, ahead-of-print. doi:10.1108/JIC-06- 20200204

Alvino, F., Di Vaio, A., Hassan, R. \& Palladino, R. (2020). Intellectual capital and sustainable development: A systematic literature review. Journal of Intellectual Capital, 22(1), 76-94. doi:10.1108/JIC-11-2019-0259

Amores-Salvadó, J., Cruz-González, J., \& Delgado-Verde, M. - M. (2021). Green technological distance and environmental strategies: the moderating role of green structural capital. Journal of Intellectual Capital., ahead-of-print. doi:10.1108/JIC-06-2020-0217

Astuti, P. \& Datrini, L. (2021). Green competitive advantage: Examining the role of environmental consciousness and green intellectual capital. Management Science Letters, 11(4), 1141- 1152.

Augustine, Y. \& Dwianika, A. (2019). Earnings Management In Indonesia: Determinant Of Company Size, Structure Of Managerial Ownership And Profitability On Earnings Management With Asymmetry Information And Green Intellectual Capital As Moderating Variables. South East Asia Journal of Contemporary Business, Economics and Law, 19(5), 176.

Bombiak, E. (2021). Assessment of the level of green intellectual capital development-Polish enterprises case study. European Research Studies, 24(1), 1139-1156.

Bontis, N. (1999). Managing organizational knowledge by diagnosing intellectual capital: framing and advancing the state of the field. International Journal of Technology Management, 18(433463), 267-297. doi:10.1504/IJTM.1999.002780

Cahyono, B. \& Hakim, A. (2020). Green intellectual capital and competitive advantage: the moderating effect of Islamic business ethics. 3rd Asia Pacific International Conference of Management and Business Science. 3, pp. 78-84. Atlantis Press. doi:10.2991/aebmr.k.200410.013 
Cavicchi, C. \& Vagnoni, E. (2017). Does intellectual capital promote the shift of healthcare organizations towards sustainable development? Evidence from Italy. Journal of Cleaner Production, 153, 275-286.

Chang, C. H. \& Chen, Y. S. (2012). The determinants of green intellectual capital. Management Decision, 50(1), 74-94. doi:10.1108/00251741211194886

Chaudhry, N. I., Bilal, A., Awan, M. U. \& Bashir, A. (2016). The role of environmental consciousness, green intellectual capital management and competitive advantage on financial performance of the firms: an evidence from manufacturing sector of Pakistan. Journal of Quality and Technology Management, 13(II), 51-70.

Chen, Y. (2008). The positive effect of green intellectual capital on competitive advantage of firms. Journal of Business Ethics, 77(3), 271-286.

Delgado-Verde, M., Amores-Salvadó, J., Martín-de Castro, G. \& Navas-López, J. E. (2014). Green intellectual capital and environmental product innovation: the mediating role of green social capital. Knowledge Management Research \& Practic, 12(3), 261-275.

Dumay, J. \& Garanina, T. (2013). Intellectual capital research: A critical examination of the thirdstage. Journal of Intellectual Capital, 14(1), 10-25.

Elkington, J. (1997). Cannibals with forks. The triple bottom line of 21st century, 73.

Erinos, N. R. \& Yurniwati, Y. (2018). Green intellectual capital and financial performance of corporate manufacture in Indonesia. International Journal of Business and Management Invention. 6 (2), pg. 75-81. PICEEBA. doi:10.2991/piceeba-18.2018.79

Guthrie, J., Ricceri, F. \& Dumay, J. (2012). Reflections and projections: A decade of intellectualcapital accounting research. The British Accounting Review, 44(2), 68-82.

Hart, S. L. (1995). A natural-resource-based view of the firm. Academy of Management Review, 20(4), 986-1014. doi:10.2307/258963

Hermawan, S., Harinyanto, W. \& Biduri, S. (2020). Intellectual capital, business performance, and competitive advantage: an empirical study for the pharmaceutical companies. Journal of Management System, 48(1), 103-106. doi:10.1108/00251741011014481

Huang, C. L. \& Kung, F. H. (2011). Environmental consciousness and intellectual capital management: Evidence from Taiwan's manufacturing industry. Management Decision, 49(9), 1405-1425. doi:10.1108/00251741111173916

Isil, O. \& Hernke, M. T. (2017). The triple bottom line: A critical review from a transdisciplinary perspective. Business Strategy and the Environment, 26(8), 1235-1251.

Jerez-Gomez, P., Céspedes-Lorente, J. \& Valle-Cabrera, R. (2005). Organizational learning capability: a proposal of measurement. Journal of Business Research, 58(6), 715-725.

Jin, Y., Cheng, C. \& Zeng, H. (2020). Is evil rewarded with evil? The market penalty effect of corporate environmentally irresponsible events. Business Strategy and the Environment, 29(3), 846-871.

Jirakraisiri, J., Badir, Y. F. \& Frank, B. (2021). Translating green strategic intent into green process innovation performance: the role of green intellectual capital. Journal of Intellectual Capital, 22(7), 43-67.

Khan, N. U., Anwar, M. L. \& Khattak, M. S. (2021). Intellectual capital, financial resources, and green supply chain management as predictors of financial and environmental performance. Environmental Science and Pollution Research, 28(16), 19755-19767.

Malik, S. Y., Mughal, Y. H., Kundi, G. M., Mughal, M. H. \& Ramayah, T. (2020). Pathways towards sustainability in organizations: Empirical evidence on the role of green human resource management practices and green intellectual capital. Sustainability, 12(8), 3228.

Mansoor, A., Jahan, S. \& Riaz, M. (2021). Does green intellectual capital spur corporate environmental performance through green workforce? Journal of Intellectual Capital, aheadof-print. 
Martín-de Castro, G., González-Masip, J. J. \& Fernández-Menéndez, J. (2020). The role of corporate environmental commitment and STP on technological talent recruitment in service firms. Knowledge Management Research \& Practice, 1-14.

Martins, V. W., Rampasso, I. S., Anholon, R., Quelhas, O. L. \& Leal Filho, W. (2019). Knowledge management in the context of sustainability: Literature review and opportunities for future research. Journal of Cleaner Production, 229, 489-500.

Meadows, D., Meadows, D. \& Randers, J. (1993). Beyond the Limits: Confronting Global Collapse, envisioning a sustainable future. Vt: Chelsea Green Pub. Co.

Minoja, M. R. (2021). Managing intellectual capital for sustainability: Evidence from a Remunicipalized, publicly owned waste management firm. Journal of Cleaner Production, 279, 123213.

Murillo-Luna, J. L., Garcés-Ayerbe, C. \& Rivera-Torres, P. (2008). Why do patterns of environmental response differ? A stakeholders' pressure approach. Strategic Management Journal, 29(11), 1225-1240.

Nisar, Q. A., Haider, S., Ali, F., Jamshed, S., Ryu, K. \& Gill, S. S. (2021). Green human resource management practices and environmental performance in Malaysian green hotels: The role of green intellectual capital and pro-environmental behavior. Journal of Cleaner Production, 22(1), 311, 127504.

Nivlouei, F. B. \& Khass, E. D. (2014). The role of green intellectual capital management in acquiring green competitive advantage for companies. International Journal of Management Research and Development (IJMRD), 4(2).

Omar, M. K., Mohd Yusoff, Y. \& Kamarul Zaman, M. D. (2019). The effect of organizational learning capability as a mediating variable in the relationship between green intellectual capital and business sustainability: evidence from the manufacturing sector. International Journal of Academic Research in Business and Social Sciences, 9(6), 584-599.

Popescu, C. R. (2019). Addressing IC in the Context of Integrated Strategy and Performance: Emphasizing the Role of Companies' Unique Value Creation Mechanism, While Targeting Better Organizational Reporting in Romania: The Case of Green Marketing and Green Marketing Strategies. Journal of Marketing Research and Case Studies, 2019. doi:10.5171/2019.672821

Rehman, S. U., Kraus, S., Shah, S. A., Khanin, D. \& Mahto, R. V. (2021). Analyzing the relationship between green innovation and environmental performance in large manufacturing firms. Technological Forecasting and Social Change, 163, 120481.

Sabir, M. R., Rehman, M. \& Asghar, W. (2020). Assessing the Mediating Role of Organization Learning Capability between the Relationship of Green Intellectual Capital and Business Sustainability. Journal of Business and Social Review in Emerging Economies, 6(4), 12891301.

Secundo, G., Massaro, M., Dumay, J. \& Bagnoli, C. (2018). Intellectual capital management in the forth stage of IC research. Journal of Intellectual Capital, 19 (1), 157-177.

Secundo, G., Ndou, V., Del Vecchio, P. \& De Pascale, G. (2020). Sustainable development, intellectual capital and technology policies: A structured literature review and future research agenda. Technological Forecasting and Social Change, 153, 119917.

Shah, S. M., Ahmed, U., Ismail, A. I. \& Mozammel, S. (2021). Going Intellectually Green: Exploring the Nexus between Green Intellectual Capital, Environmental Responsibility, and Environmental Concern towards Environmental Performance. Sustainability, 13(11), 6257.

Shang, K. C., Chen, S. Y., Ye, K. D. \& Yu, H. Y. (2019). Green dynamic capabilities-the necessity between green intellectual capital and firm performance: Evidence from Taiwan's manufacturing sector. Journal of Southwest Jiaotong University, 39(2), 37-67.

Sidik, M. H., Yadiati, W., Lee, H. \& Khalid, N. (2019). The dynamic association of energy, environmental management accounting and green intellectual capital with corporate 
environmental performance and competitive. International Journal of Energy Economics and Policy, Vol 9, no. 5.

Song, W. \& Yu, H. (2018). Green innovation strategy and green innovation: The roles of green creativity and green organizational identity. Corporate Social Responsibility and Environmental Management, 25(2), 135-150.

Trevlopoulos, N. S., Tsagarakis, K. P., Vatalis, K. I. \& Nikolaou, I. E. (2021). The influence of environmental regulations on business innovation, intellectual capital, environmental and economic performance. Environment Systems and Decisions, 41(1), 163-178.

Ullah, H., Wang, Z., Bashir, S., Khan, A. R., Riaz, M. \& Syed, N. (2021). Nexus between IT capability and green intellectual capital on sustainable businesses: evidence from emerging economies. Environmental Science and Pollution Research, 28(22), 27825-27843.

Villiers, C. \&. (2020). A critical reflection on the future of financial, intellectual capital. Critical Perspectives on Accounting, 70, 1-13. doi:10.1016/j.cpa.2017.05.003

Wang, C. H. \& Juo, W. J. (2021). An environmental policy of green intellectual capital: Green innovation strategy for performance sustainability. Business Strategy and the Environment.

Yadiati, W. (2019). The role of green intellectual capital and organizational reputation in influencing environmental performance. International Journal of Energy Economics and Policy, 9(3). doi:10.32479/ijeep.7752

Yahya, N. A., Arshad, R. \& Kamaluddin, A. (2015). Green intellectual capital resources as drivers of firms' competitive advantage. International Conference on Intellectual Capital and Knowledge Management and Organisational Learning. 5(2), pg. 327-335. Academic Conferences International Limited.

Yasmeen, H., Wang, Y., Zameer, H. \& Ismail, H. (2020). Modeling the role of government, firm, and civil society for environmental sustainability. International Journal of Agricultural and Environmental Information Systems, pg. 62-83. doi:10.4018/IJAEIS.2019040104

Yong, J., Yusliza, M., Ramayah, T. \& Fawehinmi, O. (2019). Nexus between green intellectual capital and green human resource management. Journal of Cleaner Production, 215, 364-374.

Yusliza, M. Y., Yong, J. Y., Tanveer, M. I., Ramayah, T., Faezah, J. N. \& Muhammad, Z. (2020). A structural model of the impact of green intellectual capital on sustainable performance. Journal of Cleaner Production, 249, 119334.

Yusoff, Y. M., Omar, M. K., Zaman, M. D. \& Samad, S. (2019). Do all elements of green intellectual capital contribute toward business sustainability? Evidence from the Malaysian context using the Partial Least Squares method. Journal of Cleaner Production, 234, 626-637.

Zameer, H., Wang, Y. \& Yasmeen, H. (2020). Reinforcing green competitive advantage through green production, creativity and green brand image: implications for cleaner production in China. Journal of Cleaner Production, 247, 119119. 